\title{
Optimum Design of Slotted Axial Flux Internal Stator Motor Using Genetic Algorithm for Electric Vehicle
}

\author{
${ }^{1}$ S.Asghar Gholamian, ${ }^{2}$ M. Ardebili , ${ }^{2}$ K. Abbaszadeh \\ and ${ }^{3}$ Seyyed Akbar Gholamian \\ ${ }^{1}$ Electrical and Computer Engineering Department of Babol University of Technology, \\ Babol, Iran. \\ ${ }^{2}$ Electrical Engineering Department of K.N. Toosi University of Technology, \\ Tehran, Iran. \\ ${ }^{3}$ Department of Industrial Engineering, Payame Noor University, \\ Babol, Iran.
}

Name and E-mail of Corresponding Author: S. Asghar Gholamian and gholamian@nit.ac.ir

\begin{abstract}
Axial flux permanent magnet motors having a dual air-gap configuration have been designed and constructed to achieve high power density and used in industries interestingly and specially in the system of driving electrical vehicles. In this paper, the equation related to the design and dimensions of double-sided slotted axial flux synchronous motor with internal stator (TORUS) will be investigated. Then, an optimum design based on genetic algorithm with the purpose of increasing power density is presented. Twodimensional finite-element analysis (FEM) is used to demonstrate these optimization and its results will be presented. Finally, it presents the resultant back emf waveform and current for a $1.0 \mathrm{~kW}, 48 \mathrm{~V}, 50 \mathrm{~Hz}, 4-$ poles/15-slots TORUS slotted axial motor prototype, based on our optimization techniques.
\end{abstract}

\section{KEYWORDS}

Axial Flux PM Motors (AFPM), Power Density, Genetic Algorithm and Finite Element method (FEM)

\section{INTRODUCTION}

Electrical motor is one of the most important parts in industrial. Thus, improving its operation is necessary and essential. Electrical motors are designed and built in various Configurations. These Configurations of motors have many various motors that divided two groups Axial flux PM Motor (AFPM) and Radial flux PM Motor (RFPM). Axial flux PM Motor are different because of direction of flux movement with electrical usual machine because in these motors flux move parallel with machine shaft $[1,2]$.

Now days, due to its disc-shaped structure and extremely high compactness the axial-flux permanent-magnet machine (AFPM) topology is particularly suited for wheel direct-drive motor applications $[12,13]$. The required electric motors in vehicles should have the features like, proper shape, low volume, high torque and power density, high reliability and high efficiency. In comparison that accomplished between axial flux motors and electric machines, the axial flux 
motors can be the best choice to be used in electrical vehicles [4]. For this cause many design of this motors built by researcher [7, 8, 10 and 12].

Among the different configurations of axial flux motors, double-sides configuration, has the best and the most application. Thus axial flux motor are designed with slotted stators and without slot, that the slot configuration has the higher strength and power density that without one [1,4 and 9]. In this paper, the equations of design and dimensions of a double-sided slotted axial flux synchronous motor with internal stator (TORUS) will be investigated. A simplified model of axial-flux TORUS motor is shown in Fig. 1. Then, a genetic algorithm, as a way of powerful optimization is used for optimizing the design of motor. The goal function in this process is optimizing power density (power per volume unit) sinusoidal back emf. In the following; the results of written program for optimization has been investigated by finite element method (FEM) and its consequences will be compared. In the following, it presents the resultant back emf waveform and current for a $1.0 \mathrm{~kW}, 48 \mathrm{~V}$ TORUS slotted axial motor prototype. Finally, the paper discusses design and construction of the motor prototype and reports experimental results taken from the machine laboratory tests.

It should be mentioned that in this article, software MATLAB7, was used for programming and software MAXWEELL10 was used for simulation of finite element method (FEM) and all designing limits were considered.

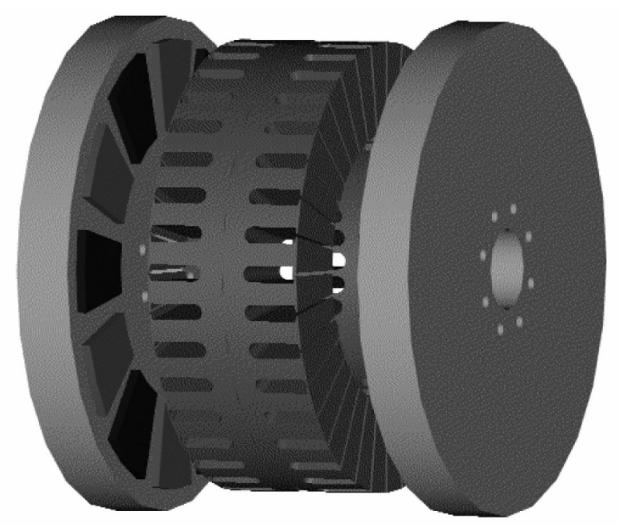

Fig.1. simplified model of double-sided slotted axial flux synchronous motor with internal stator (TORUS)

\section{AFPM motors and Design Algorithm}

Axial flux permanent magnetic motors have single-sided, double-sided and multi-sided structures. An easiest and cheapest structure of axial flux motors is single-sided. But because of producing low moment and bearing problem that result from high magnetism in air levels that causes closing two parts to each other using from this Configuration is not usual. We can defuse high magnetism between Rotor and Stator by using from second Stator or rotor that set up by first symmetrical. This structure called double-sided. Double-sided motors are the best and used more than others. Despite this fact that double-sided are suitable but any Configuration of several sides is the best solution for special application. For example, in cases that we need to high power with much limitation on outside diameter, increasing the number of disks is a good suggestion.

Slotted AFPM motors can be used as a stimulant part of electric vehicle because have featured like: low volume, high configuration, high torque, power density and high efficiency. A typical 
configuration of a TORUS slotted topologies at the average diameter in 2D is presented in Fig.1. More details of this configuration are discussed in [1, 4 and 5].

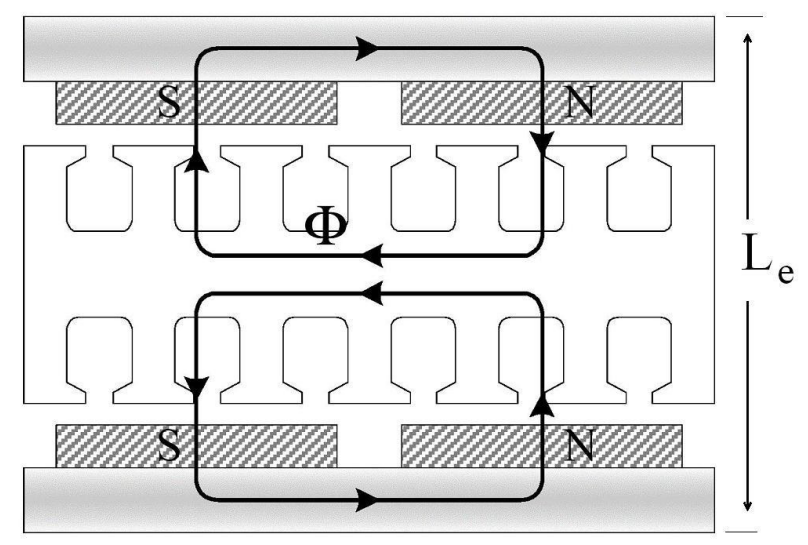

Fig.1. Typical configuration of a slotted TORUS at the average diameter in 2D

In this structure stator armature winding is as permanent magnet synchronous motors and permanent magnetic are placed surface of the rotor.

\subsection{Sizing Equation of AFPM Motors}

In general, if stator leakage inductance and resistance are neglected, the output power for any electrical machine can be expressed as

$$
P_{\text {out }}=\eta \frac{m}{T} \int_{0}^{T} e(t) . i(t) d t=m K_{p} \eta E_{p k} I_{p k}
$$

Where $e(t)$ and $\mathrm{E}_{\mathrm{pk}}$ are phase air gap EMF and its peak value, $\mathrm{i}(\mathrm{t})$ and $\mathrm{I}_{\mathrm{pk}}$ are phase current and the peak phase current, $\eta$ is machine efficiency, $m$ is number of phases of the machine and $T$ is period of one cycle of the EMF[1,2].

The quantity $\mathrm{K}_{\mathrm{p}}$ is termed the electrical power waveform factor and defined as

$$
K_{p}=\frac{1}{T} \int_{0}^{T} \frac{e(t) \times i(t)}{E_{p k} \times I_{p k}} d t=\frac{1}{T} \int_{0}^{T} f_{e}(t) \cdot f_{i}(t) d t
$$

Where $\mathrm{f}_{\mathrm{e}}(\mathrm{t})=\mathrm{e}(\mathrm{t}) / \mathrm{E}_{\mathrm{pk}}$ and $\mathrm{f}_{\mathrm{i}}(\mathrm{t})=\mathrm{i}(\mathrm{t}) / \mathrm{I}_{\mathrm{pk}}$ are the expressions for the normalized EMF and current waveforms. In order to indicate the effect of the current waveform, a definition for current waveform factor, $\mathrm{K}_{\mathrm{i}}$, is also useful,

$$
K_{i}=\frac{I_{p k}}{I_{r m s}}=\left[\frac{1}{T} \int_{0}^{T}\left(\frac{i(t)}{I_{p k}}\right)^{2} d t\right]^{-0.5}
$$

Where $\mathrm{I}_{\mathrm{rms}}$ is the rms value of the phase current. The peak value of the phase air gap EMF for AFPM in (1) is given by:

$$
E_{p k}=K_{e} N_{p h} B_{g} \cdot \frac{f}{p} \cdot\left(1-\lambda^{2}\right) D_{o}^{2}
$$

Where $\mathrm{K}_{\mathrm{e}}$ is the EMF factor which incorporates the winding distribution factor $\mathrm{K}_{\mathrm{w}}$ and the per unit portion of the total air gap area spanned by the salient poles of the machine (if any), $\mathrm{N}_{\mathrm{ph}}$ is the number of turn per phase, $\mathrm{Bg}$ is the flux density in the air gap, $\mathrm{f}$ is the converter frequency, $\mathrm{p}$ is the machine pole pairs, $\lambda$ is the diameter ratio for AFPM defined as $D_{i} / D_{0}, D_{0}$ is the diameter 
of the machine outer surface, $D_{i}$ is the diameter of the machine inner surface. The peak phase current in (1) is given by:

$$
I_{p k}=A \pi K_{i} \frac{1+\lambda}{2} \cdot \frac{D_{o}}{2 m_{1} N_{p h}}
$$

Where $\mathrm{m}_{1}$ and $\mathrm{A}$ are number of phases and the electrical loading. Combining (1) through (5), the general purpose sizing equations take the following form for AFPM.

$$
P_{\text {out }}=\frac{m}{m_{1}} \frac{\pi}{2} K_{e} K_{p} K_{i} A B_{g} \eta \frac{f}{p}\left(1-\lambda^{2}\right)\left(\frac{1+\lambda}{2}\right) D_{o}^{3}
$$

The machine power density for the total volume can be defined as

$$
P_{\text {den }}=\frac{P_{\text {out }}}{\frac{\pi}{4} D_{\text {tot }}^{2} L_{\text {tot }}}
$$

Where $D_{\text {tot }}$ is the total machine outer diameter including the stack outer diameter and the protrusion of the end winding from the iron stack in the radial direction, $\mathrm{L}_{\text {tot }}$ is the total length of the machine including the stack length and the protrusion of the end winding from the iron stack in the axial direction [1,2 and 9].

The outer surface diameter $D_{o}$ can be written as

$$
D_{o}=\left(P_{\text {out }} / \frac{\pi m}{2 m_{1}} K_{e} K_{p} K_{i} A B_{g} \eta \frac{f}{p}\left(1-\lambda^{2}\right)\left(\frac{1+\lambda}{2}\right)\right)^{1 / 3}
$$

The machine total outer diameter $\mathrm{D}_{\text {tot }}$ for the TORUS motor is given by

$$
D_{t o t}=D_{o}+2 W_{c u}
$$

Where $\mathrm{W}_{\mathrm{cu}}$ is the protrusion of the end winding from the iron stack in the radial direction. For the back-to-back wrapped winding, protrusions exist toward the axis of the machine as well as towards the outsides and can be calculated as

$$
W_{c u}=\frac{D_{i}-\sqrt{D_{i}^{2}-\left(2 A D_{g} / K_{c u} J_{s}\right)}}{2}
$$

Where $\mathrm{D}_{\mathrm{g}}$ is the average diameter of the machine, $\mathrm{J}_{\mathrm{s}}$ is the current density and $\mathrm{K}_{\mathrm{cu}}$ is the copper fill factor. The axial length of the machine $\mathrm{L}_{\mathrm{e}}$ is given by

$$
L_{e}=L_{s}+2 L_{r}+2 g
$$

Where $L_{s}$ is axial length of the stator, $L_{r}$ is axial length of the rotor and $g$ is the air gap length. The axial length of the stator $\mathrm{L}_{\mathrm{s}}$ is

$$
L_{s}=L_{c s}+2 L_{s s}
$$

Note for the slotted topology machines the depth of the stator slot for slotted motors is $\mathrm{L}_{\mathrm{ss}}=\mathrm{W}_{\mathrm{cu}}$.

The axial length of the stator core $L_{c s}$ can be written as

$$
L_{c s}=\frac{B_{g} \pi \alpha_{p} D_{o}(1+\lambda)}{4 p B_{c s}}
$$

Where $B_{c s}$ is the flux density in the stator core and $\alpha_{p}$ is the ratio of average air gap flux density to peak air gap flux density.

The axial length of rotor $L_{\mathrm{r}}$ becomes

$$
L_{r}=L_{c r}+L_{P M}
$$

Also, the axial length of the rotor core $\mathrm{L}_{\mathrm{cr}}$ is

$$
L_{c r}=\frac{B_{u} \pi D_{o}(1+\lambda)}{8 p B_{c r}}
$$

Where $\mathrm{B}_{\mathrm{cr}}$ is the flux density in the rotor disc core, and $\mathrm{B}_{\mathrm{u}}$ is the attainable flux density on the surface of the PM.

The PM length $\mathrm{L}_{\mathrm{PM}}$ can be calculated as 


$$
\mathrm{L}_{\mathrm{PM}}=\frac{\mu_{\mathrm{r}} \mathrm{B}_{\mathrm{g}}}{\mathrm{B}_{\mathrm{r}}-\left(\frac{\mathrm{B}_{\mathrm{g}}}{\mathrm{K}_{\mathrm{d}} \mathrm{K}_{\mathrm{f}}}\right)} \mathrm{K}_{\mathrm{c}} \mathrm{g}
$$

Where $\mu_{r}$ is the recoil relative permeability of the magnet, $\mathrm{B}_{\mathrm{r}}$ is the residual flux density of the PM material, $K_{d}$ is the leakage flux factor, $K_{c}$ is the Carter factor, $K_{f}=B_{g p k} / B_{g}$ is the peak value corrected factor of air gap flux density in radial direction of the AFPM motor. These factors can be obtained using FEM analysis [1,2 and 9].

\subsection{Design Process}

In design process regarding the design parameter and the existing limitations, first the external diameter of motor is estimated then, by using relations (8) to (16), total axial length and external diameter will be determined and motor volume and power density of relation (7) will be estimated.

It should be mentioned that if in design method, the limitations are not established, design parameters will be changed in a guided method, that the algorithm going to answer these limitations.

\subsection{Limitation parameters}

These parameter that are characteristics and physical dimensions of motor, are considered as the basis for designing. Some of these parameters, naturally, and others with limitations can't change very much. Some of these restrictions of design limitations and others are distinguished by ordering customer. Those are as follows:

A) Flux density limitation in core: $B \leq B_{\max }$

B) Limitation of $\lambda=D_{i} / D_{O}: \lambda_{\min } \leq \lambda \leq \lambda_{\max }$

C) Limitation of air gap: $g_{\min } \leq g \leq g_{\max }$

D) Limitation of axial length: $L_{e} \leq L_{e, \max }$

E) Limitation of terminal voltage: $V_{\min } \leq V \leq V_{\max }$

From the above cases, limitations (A), (B) and (C) are for design and related standards and others are related to the ordering customer.

\section{Genetic algorithm and optimization}

Genetic algorithm (GA) is used a powerful optimization tool, in many different optimization problems GA is a search algorithm that is based on natural selection mechanisms and natural genetics. For using GA, parameters are coded to arrays with specific length in solution area. Each array has a definite fitness that depends on the application. Then GA search to find the optimal solution. GA includes chromosome representation of solution, initializing the first generation, cross over and mutation operators that considering the problem to be optimized, these parameters are defined. According to the illustrations at the beginning of this section, parameters of GA are coded as below $[1,11]$. 
International Journal of Software Engineering \& Applications (IJSEA), Vol.2, No.3, July 2011

\subsection{Chromosome representation}

Each chromosome in proposed GA is an $1 \times 8$ array as shown in Fig.3.

\begin{tabular}{|l|l|l|l|l|l|l|l|}
\hline $\mathrm{B}_{\mathrm{g}}$ & $\lambda$ & $\mathrm{g}$ & $\mathrm{A}$ & $\mathrm{K}_{\mathrm{w}}$ & $\mathrm{N}_{\mathrm{ph}}$ & $\tau_{\mathrm{p}}$ & $\gamma$ \\
\hline
\end{tabular}

Fig.3. Chromosome representation

In which $\mathrm{g}, \mathrm{N}_{\mathrm{ph}}, \mathrm{A}, \mathrm{K}_{\mathrm{w}}, \lambda, \tau_{p}, \gamma$ and $\mathrm{B}_{\mathrm{g}}$ are air gap length, number of turn per phase, electrical loading, winding factor, diameter ratio, pole arc ratio, skewing angle and flux density of air gap, respectively.

\subsection{Cross over}

For instance, considering two point cross over in Fig.4. There is not the possibility of mutation in the proposed algorithm. In this paper, the method of elitist strategy is used as the selection operator.

\begin{tabular}{|c|c|c|c|c|c|c|c|l}
\hline $\mathrm{B}_{\mathrm{g}}$ & $\lambda$ & $\mathrm{g}$ & $\mathrm{A}$ & $\mathrm{K}_{\mathrm{W}}$ & $\mathrm{N}_{\mathrm{ph}}$ & $\tau_{\mathrm{p}}$ & $\gamma$ & Parent 1 \\
\hline \hline $\mathrm{B}_{\mathrm{g}}^{\prime}$ & $\lambda^{\prime}$ & $\mathrm{g}^{\prime}$ & $\mathrm{A}^{\prime}$ & $\mathrm{K}_{\mathrm{W}}^{\prime}$ & $\mathrm{N}_{\mathrm{ph}}^{\prime}$ & $\tau_{\mathrm{p}}^{\prime}$ & $\gamma^{\prime}$ & Parent 2 \\
\hline $\mathrm{B}_{\mathrm{g}}^{\prime}$ & $\lambda^{\prime}$ & $\mathrm{g}$ & $\mathrm{A}$ & $\mathrm{K}_{\mathrm{W}}$ & $\mathrm{N}_{\mathrm{ph}}$ & $\tau_{\mathrm{p}}^{\prime}$ & $\gamma^{\prime}$ & Children 1 \\
\hline \hline $\mathrm{B}_{\mathrm{g}}$ & $\lambda$ & $\mathrm{g}^{\prime}$ & $\mathrm{A}^{\prime}$ & $\mathrm{K}_{\mathrm{W}}^{\prime}$ & $\mathrm{N}_{\mathrm{ph}}^{\prime}$ & $\tau_{\mathrm{p}}^{\prime}$ & $\gamma$ & Children 2 \\
\hline
\end{tabular}

Fig.4. two point crossover

\subsection{Fitness function}

As mentioned at the beginning of this paper, the proposed algorithm will be used to find the optimum power density. The motor power density for the total volume can be defined as

$$
P_{\text {den }}=\frac{P_{\text {out }}}{\frac{\pi}{4} D_{\text {tot }}^{2} L_{e}}\left(\mathrm{~W} / \mathrm{m}^{3}\right)
$$

where, $\mathrm{D}_{\text {tot }}$ is the total machine outer diameter including the stack outer diameter and the protrusion of the end winding from the iron stack in the radial direction, $\mathrm{L}_{\mathrm{e}}$ is the total length of the machine including the stack length and the protrusion of the end winding from the iron stack in the axial direction. The schematic of the genetic algorithm optimization flow chart is shown in Fig.5. 


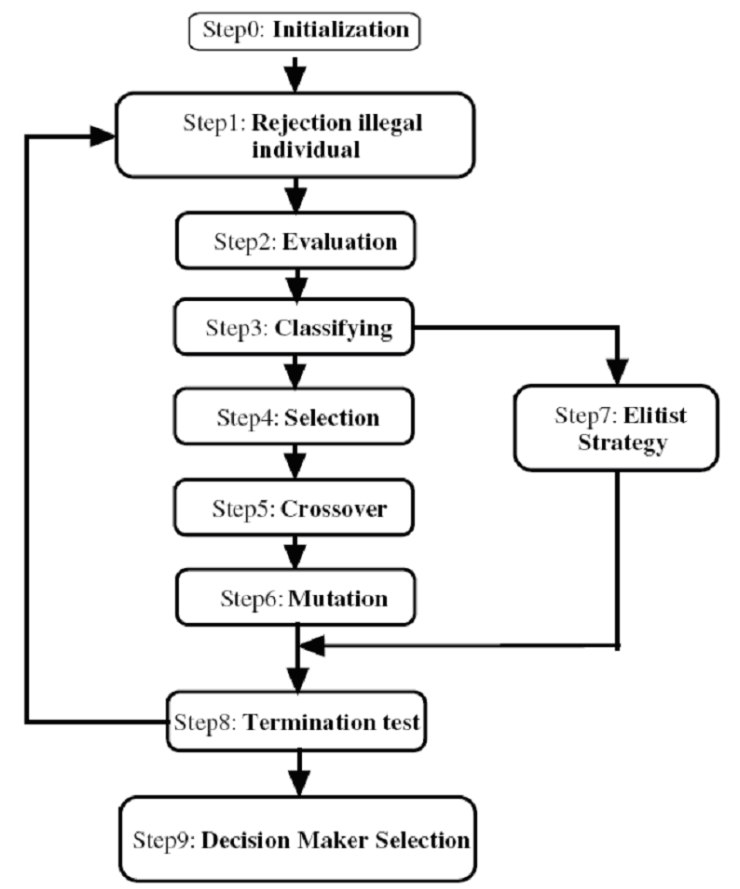

Fig.5. the schematic of the genetic algorithm flow chart

\section{Result of optimizing design by genetic algorithm}

In this section, the result of designing double-sides slotted axial flux motor is presented by genetic algorithm. Nominal design parameters of this motor and related restriction are presented in table I.

Table I

Nominal design parameters of motor

\begin{tabular}{|l|l|}
\hline design parameters & value \\
\hline Voltage & $48 \mathrm{~V}$ \\
\hline Out put power & $1 \mathrm{Kw}$ \\
\hline Number of poles & 4 \\
\hline Number of phases & 3 \\
\hline number of slots & 15 \\
\hline Slot fill factor & 0.8 \\
\hline Slot per Pole per Phase & 1.25 \\
\hline flux density in stator & $1.5 \mathrm{~T}$ \\
\hline flux density in rotor & $1.5 \mathrm{~T}$ \\
\hline Efficiency & $90 \%$ \\
\hline Residual flux density of PM & $1.1 \mathrm{~T}$ \\
\hline
\end{tabular}

By choosing generation 1400, and after executing program several times, algorithm approaches to the optimal point, variations of fitness-function (power density) for the average chromosomes in every generation are presented in Fig.6. 
International Journal of Software Engineering \& Applications (IJSEA), Vol.2, No.3, July 2011

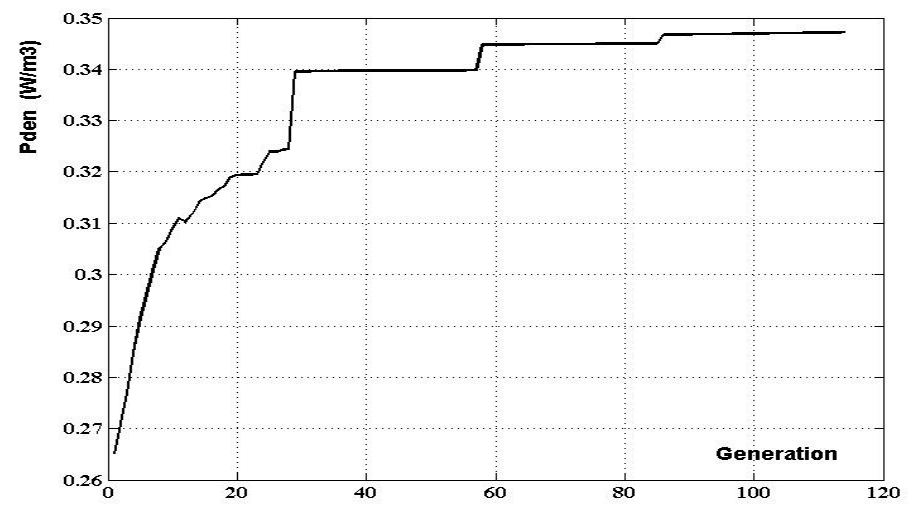

Fig.6. Average power density vs. chromosomes in each generation

By executing program and its convergence after 313 generations, the related consequences to the ranking of optimal chromosome is shown in table II that the first line shows the best choosing chromosome. Dimensions of optimal double-sides slotted axial flux motor is tabulated in TableIII.

Table II

Ranking of optimal chromosomes

\begin{tabular}{|c|c|c|c|c|c|}
\hline & Chro. 1 & Chro. 2 & Chro. 3 & Chro. 4 & Chro. 5 \\
\hline $\mathrm{P}_{\text {den }}\left(\mathrm{W} / \mathrm{cm}^{3}\right)$ & 0.36 & 0.36 & 0.36 & 0.36 & 0.36 \\
\hline $\mathrm{N}_{\mathrm{ph}}($ Turn $)$ & 90 & 83 & 70 & 72 & 69 \\
\hline $\mathrm{A}(\mathrm{A} / \mathrm{m})$ & 18600 & 17700 & 15100 & 16200 & 16500 \\
\hline $\mathrm{g}(\mathrm{mm})$ & 1.52 & 1.01 & 1.1 & 1.3 & 1.29 \\
\hline $\mathrm{B}_{\mathrm{g}}$ (Tesla) & 0.45 & 0.37 & 0.48 & 0.47 & 0.51 \\
\hline $\mathrm{K}_{\mathrm{w}}$ & 0.95 & 0.95 & 0.95 & 0.95 & 0.95 \\
\hline$\lambda$ & 0.56 & 0.52 & 0.45 & 0.44 & 0.5 \\
\hline$\tau_{p}$ & 0.65 & 0.67 & 0.7 & 0.58 & 0.6 \\
\hline$\gamma$ (deg.) & 9 & 8 & 9 & 10.5 & 9.5 \\
\hline
\end{tabular}

Table III

Dimensions of optimal double-sides slotted AFPM motor

\begin{tabular}{|l|c|}
\hline design parameters & value \\
\hline Voltage & $48 \mathrm{~V}$ \\
\hline Out put power & $1 \mathrm{KW}$ \\
\hline Number of poles & 4 \\
\hline Number of phases & 3 \\
\hline number of slots & 15 \\
\hline Power density & $0.36 \mathrm{~W} / \mathrm{cm}^{3}$ \\
\hline Outer diameter & $160 \mathrm{~mm}$ \\
\hline inner diameter & $90 \mathrm{~mm}$ \\
\hline PM length & $5 \mathrm{~mm}$ \\
\hline axial length of rotor & $18 \mathrm{~mm}$ \\
\hline axial length of stator & $15 \mathrm{~mm}$ \\
\hline protrusion of the end winding & $17 \mathrm{~mm}$ \\
\hline Slot depth & $18 \mathrm{~mm}$ \\
\hline Teeth width & $1 \mathrm{~mm}$ \\
\hline
\end{tabular}




\section{Simulation by 2D FEM}

In order to analyze the magnetic circuit and power density, 2D Finite Element Analysis was used for double-sides slotted axial flux motor. The purpose of the FEM is to get the overall picture of the saturation levels in various parts of the machine, to compare the flux densities obtained from FEM and sizing analysis $[2,5]$.

\subsection{FEM of the slotted AFPM Motor}

The motor parameters and important design dimensions used for the double-sides slotted axial flux motor model are shown in Table IV. Fig.7 shows the flux distribution over tow pole pair using FEM.

Table IV

Parameters and dimensions of slotted double-sides AFPM motor

\begin{tabular}{|l|c|}
\hline Air gap length & $1.5 \mathrm{~mm}$ \\
\hline Slot depth & $18 \mathrm{~mm}$ \\
\hline Pole-arc-ratio & 0.65 \\
\hline Axial length of stator core & $15 \mathrm{~mm}$ \\
\hline Axial length of rotor core & $18 \mathrm{~mm}$ \\
\hline Axial length of PM & $5 \mathrm{~mm}$ \\
\hline Outer diameter & $150 \mathrm{~mm}$ \\
\hline Inner diameter & $90 \mathrm{~mm}$ \\
\hline
\end{tabular}

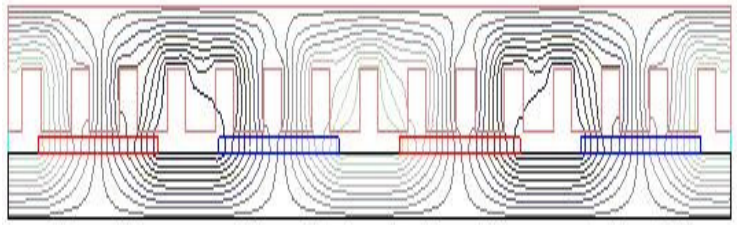

Fig.7. flux distribution over tow pole pair

Fig.8 shows the air gap Flux density over one pole at the average diameter (Dg) using FEM and Figs. 9 and 10 show the rotor and stator yoke Flux density over one pole pair at the average diameter, too.

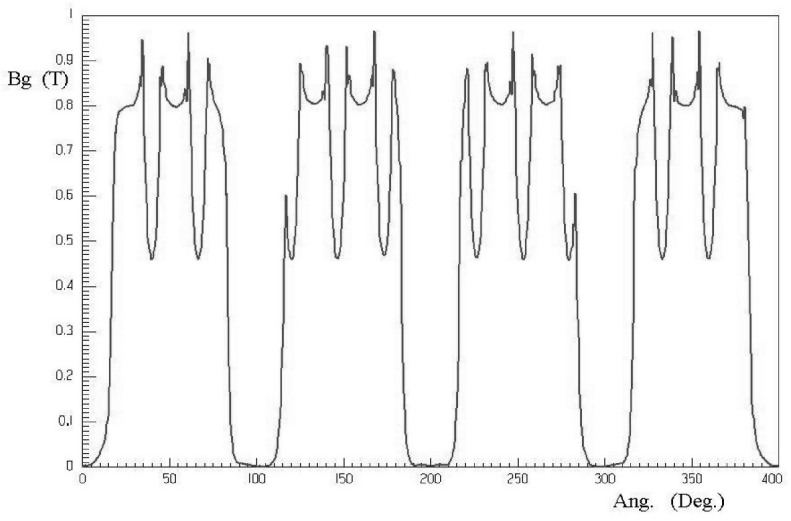

Fig8. Air gap flux density over one pole pair 
International Journal of Software Engineering \& Applications (IJSEA), Vol.2, No.3, July 2011

Average flux density comparison between the FEM results and sizing analysis results on various parts of the slotted AFPM motor at no load is tabulated in Table V.

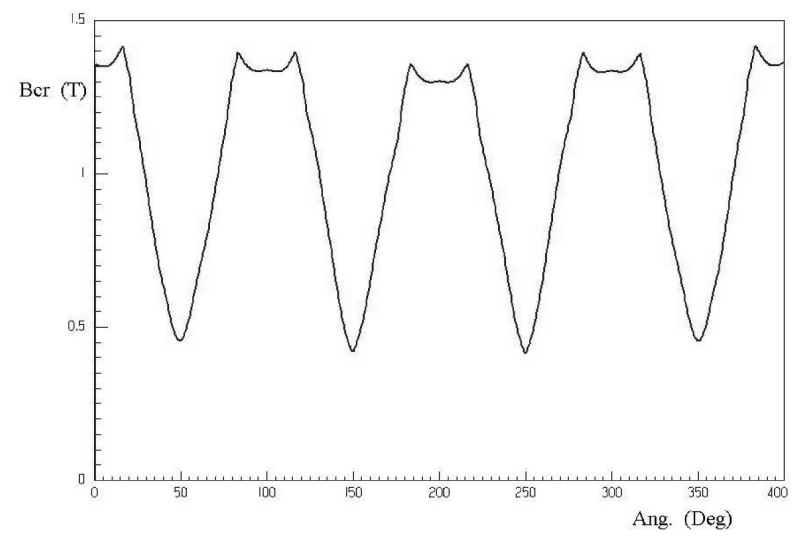

Fig.9. Rotor yoke Flux density over one pole pair

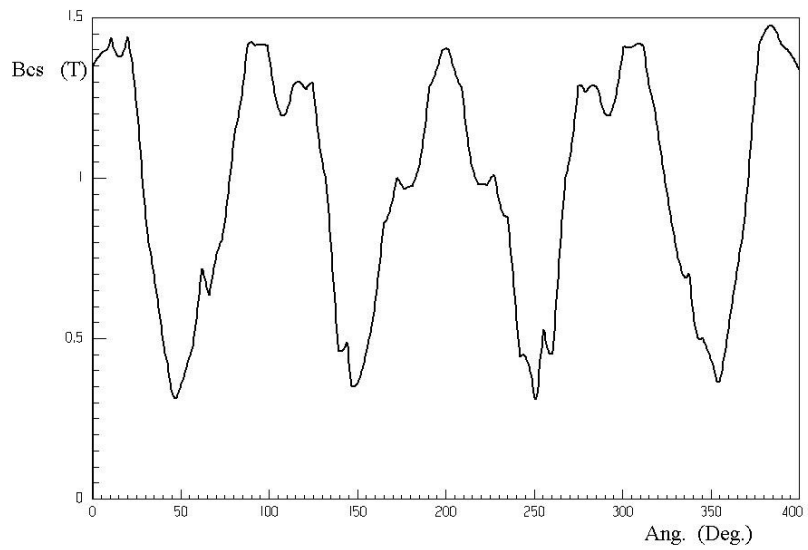

Fig.10. Stator yoke Flux density over one pole pair

The comparison table shows that the FEM results are consistent with the results obtained from the sizing analysis.

Table V

Average flux density comparison between the FEM results and sizing analysis

\begin{tabular}{|c|c|c|c|}
\hline & $\begin{array}{c}\text { Rotor } \\
\mathrm{B}_{\mathrm{cr}}\end{array}$ & $\begin{array}{c}\text { Air } \\
\text { gap } \\
\mathrm{B}_{\mathrm{ag}}\end{array}$ & $\begin{array}{c}\text { Stator } \\
\mathrm{B}_{\mathrm{cs}}\end{array}$ \\
\hline FEM & 1.42 & 0.48 & 1.44 \\
\hline Sizing Eq. & 1.5 & 0.45 & 1.5 \\
\hline Error (\%) & 5.33 & 6.66 & 4 \\
\hline
\end{tabular}

Phase Emf waveform and no load current resulting from FEM evaluation at the average diameter are shown in Fig.11 and 12, respectively. 


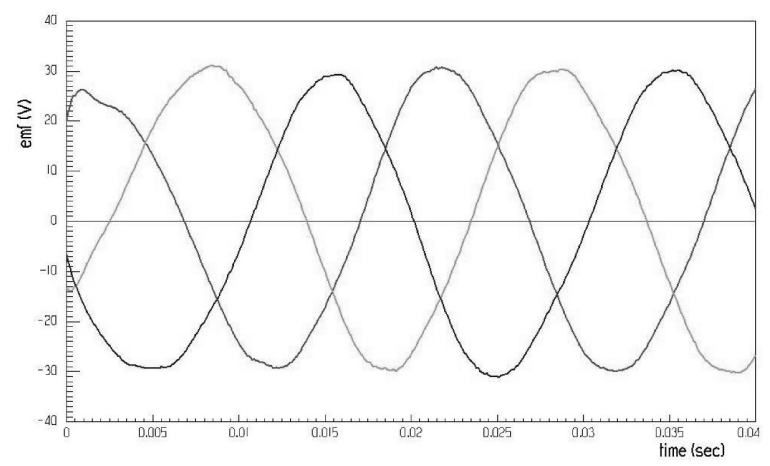

Fig.11. Phase emf waveform resulting from FEM evaluation at the average diameter

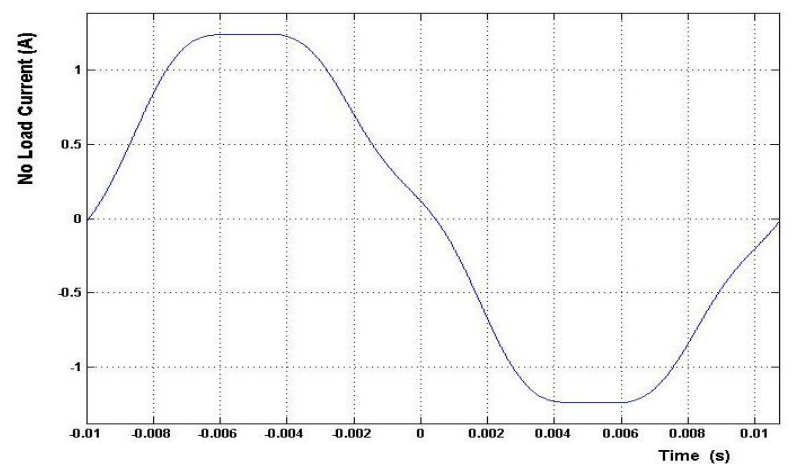

Fig.12. No load current resulting from FEM evaluation at the average diameter

\section{Prototype}

Based on the obtained results, a $1.0 \mathrm{~kW}$, 4-pole, $50 \mathrm{~Hz}$ prototype was built to optimization of power density for electric vehicle applications. The machine rotors were constructed by using mild-iron discs. Each rotor disc carries axially-magnetized Nd-Fe-B PMs, which are mounted on the disc surface faced to the machine stator. The PMs used for the construction of the machine prototype have $1.1 \mathrm{~T}$ remanence and $900 \mathrm{kA} / \mathrm{m}$ demagnetizing field. Fig. 13 shows the single disk of rotor with PMs. In this manner, the tangential and axial flux component can easily flow.

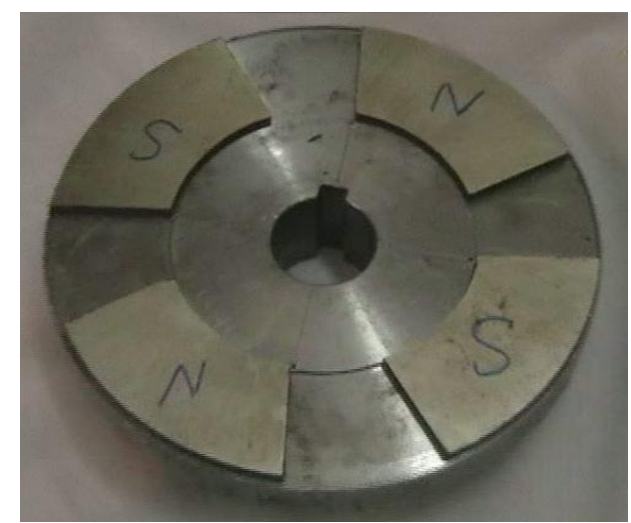

Fig.13 Single disk of rotor with PMs.

Teeth and core of stator are manufactured by silicon iron lamination in spiral construction. The stator slots are parallel sided. 
International Journal of Software Engineering \& Applications (IJSEA), Vol.2, No.3, July 2011

The core of stator befor winding and after winding with star conection is shown in Fig.14. The final assembly of prototype AFPM motor is presented in Fig. 15.

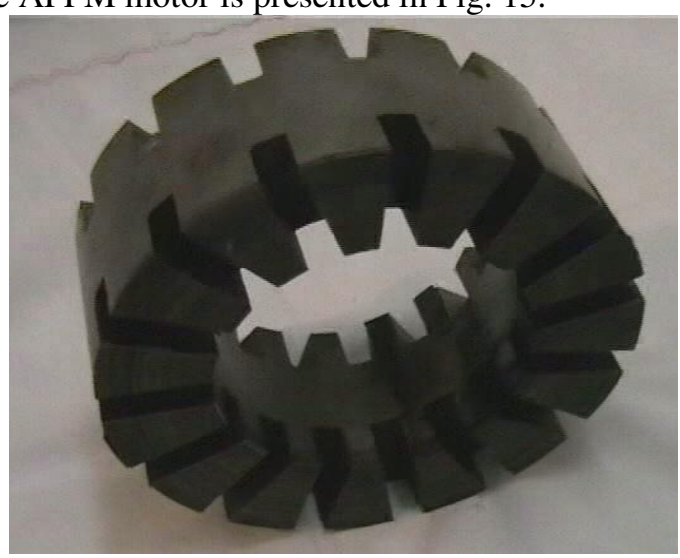

(a) Before winding

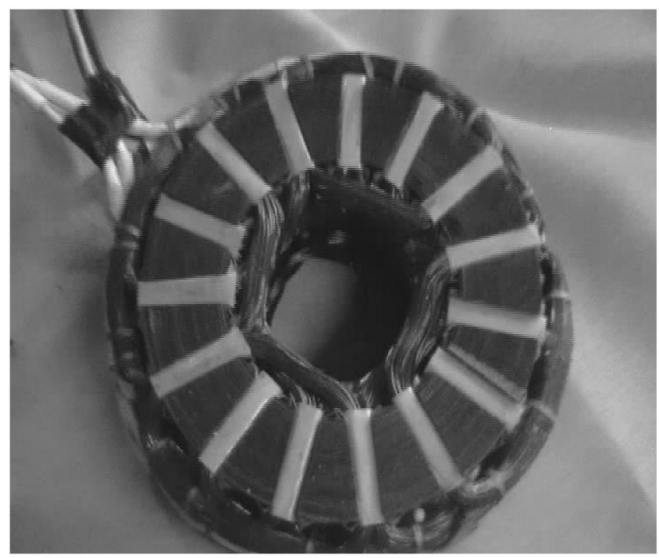

(b) After winding

Fig.14. the core of stator

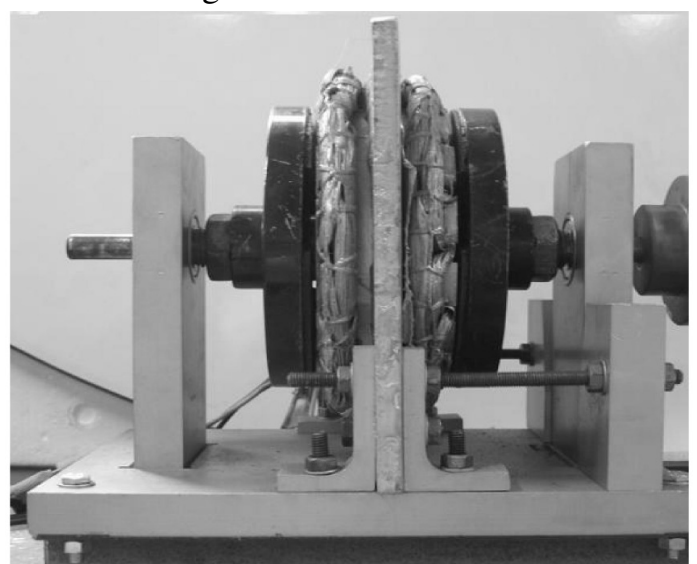

Fig.15. Final assembly of prototype AFPM motor

For obtained measurement Back emf and no load current waveform a test bench included AFPM motor and DC machine is constructed. The test bench of motor is shown in Fig.16. 
International Journal of Software Engineering \& Applications (IJSEA), Vol.2, No.3, July 2011

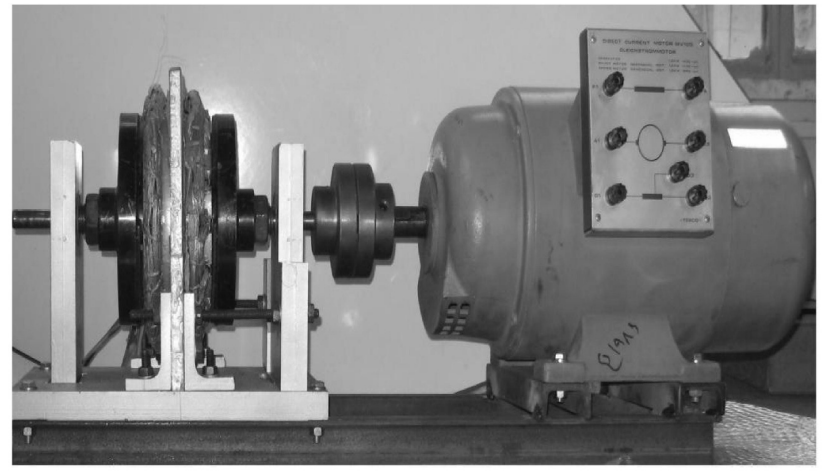

Fig.16. the test bench of motor

The measurement of the phase Back emf with its harmonic spectrum and experimental result of no load current are shown in Fig.17and 18. The comparison between the FEM and experimental results the slotted AFPM motor at no load is tabulated in Table VI.

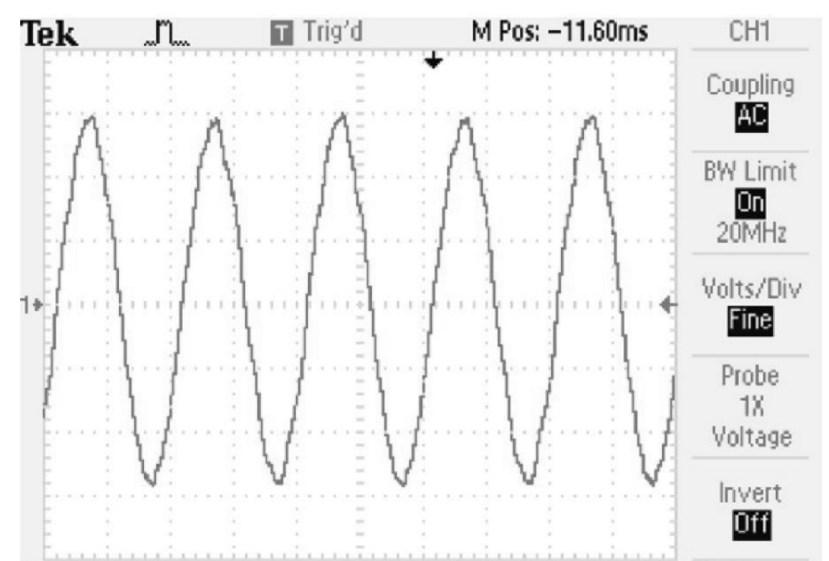

(a)

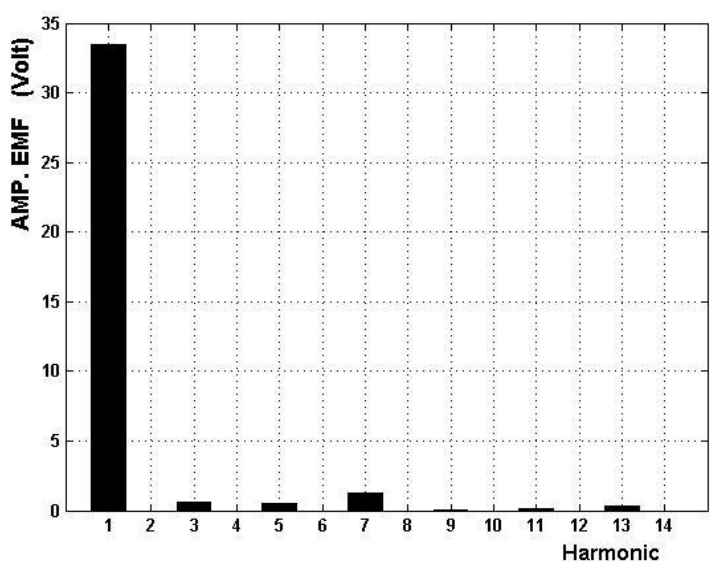

(b)

Fig.17. the back emf measurement with harmonic spectrum (voltage scale: $11 \mathrm{~V} /$ div, time scale: $10 \mathrm{~ms} /$ div) 
International Journal of Software Engineering \& Applications (IJSEA), Vol.2, No.3, July 2011

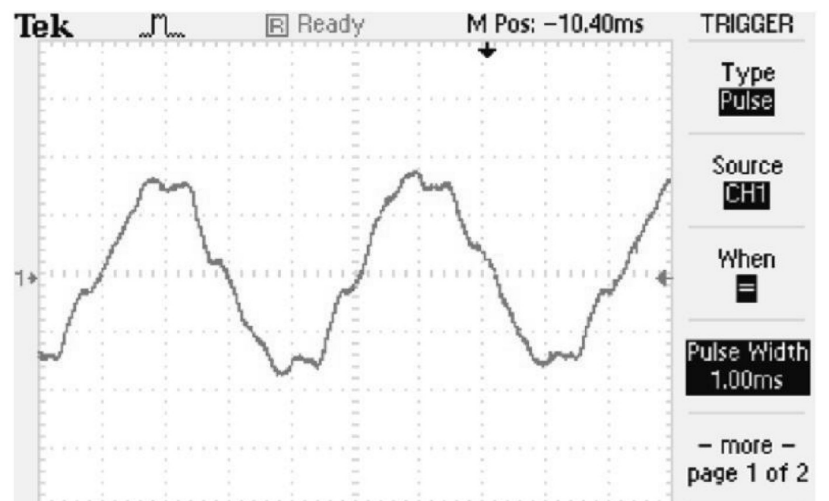

Fig.18. experimental result of no load

current (current scale: $800 \mathrm{~mA} /$ div, time scale: $5 \mathrm{~ms} / \mathrm{div}$ )

Table VI

Comparison between the FEM and experimental

\begin{tabular}{|c|c|c|c|}
\hline Back emf & $\begin{array}{c}\text { Emax } \\
(\mathrm{V})\end{array}$ & Erms (V) & THD \\
\hline Experimental & 33 & 22 & $3.5 \%$ \\
\hline FEM & 31 & 21 & $5 \%$ \\
\hline No load current & $\begin{array}{c}\text { Imax } \\
(\mathrm{A})\end{array}$ & Irms (A) & THD \\
\hline Experimental & 1.4 & 0.9 & $8.5 \%$ \\
\hline FEM & 1.3 & 0.8 & $9 \%$ \\
\hline
\end{tabular}

Compared to the finite element computation and measurement, the method of optimization and design give sufficiently accurate results.

\section{Conclusions}

In this paper, double-sides slotted axial flux motors with internal stator proposed as a part of electric vehicles because they had characteristics like, proper shape, low volume, high torque and power density, high reliability and high efficiency. Selecting an AFPM motors with higher power density is an important parameter in applications especially electric vehicles. The main goal of this paper has been optimal design of double-Sided Axial Flux Slotted PM Motors with maximum power density.

The relations of design and dimensions of this configuration of motors were investigated and among optimization methods, a genetic algorithm was used for optimization.

This paper has designed a $1 \mathrm{~kW}, 48 \mathrm{~V}$ TORUS slotted axial motor aimed to be integrated a drive system for EVs. A flux density comparison between the various parts of the optimal motor and obtained from the FEM and sizing analysis at no load agree well. Finally, the results had been used to build a $1.0 \mathrm{~kW}$, 4-poles $/ 15$-slots, $50 \mathrm{~Hz}$ axial flux motor prototype. The Back emf and no load current comparison between measurements and FEM simulation agree well, too.

\section{REFERENCES}

[1] S.A. Gholamian, M. Ardebil, K. Abbaszadeh and S. Mahmodi charati, Optimum Design of 1kW Axial Flux Permanent Magnet Slotted TORUS Motor, European Journal of Scientific Research 21 (2008) 488-499. 
International Journal of Software Engineering \& Applications (IJSEA), Vol.2, No.3, July 2011

[2] S.A. Gholamian, M. Ardebili and K. Abbaszadeh, Analytic and FEM Evaluation of Power Density for Various Types of Double-Sided Axial Flux Slotted PM Motors, International Journal of Applied Engineering Research 3 (2008) 749-762.

[3] Parag R. Upadhyay and K. R. Rajagopal, FE Analysis and Computer-Aided Design of a Sandwiched Axial-Flux Permanent Magnet Brushless DC Motor, IEEE Trans. Magn. 42 (2006) 3401 - 3403.

[4] Aydin, M.; Huang, S.; Lipo, T.A., Optimum design and 3D finite element analysis of nonslotted and slotted internal rotor type axial flux PM disc Machines, IEEE Power Engineering Society Summer Meeting 3 (2001) $1409-1416$.

[5] S. Huang, J. Luo, F. Leonardi and T. A. Lipo, "A Comparison of Power Density for Axial Flux Machines Based on the General Purpose Sizing Equation", IEEE Trans. on Energy Conversion 14 (1999) 185-192.

[6] C. C. Jensen, F. Profumo, and T. A. Lipo, A low loss permanent magnet brushless DC motor utilizing tape wound amorphous iron, IEEE Trans. Ind. Applicat. 28 (1992) 646-651.

[7] Upadhyay, P.R.; Rajagopal, K.R.; Singh, B.P,Design of a compact winding for an axial-flux permanent-magnet brushless DC motor used in an electric twowheeler, IEEE Trans. Magn. 40 (2004) $2026-2028$.

[8] Kartik Sitapati and R. Krishnan, Performance Comparisons of Radial and Axial Field PermanentMagnet, Brushless Machines, IEEE Trans. Ind. Applicat. 37 (2001) 1219-1226.

[9] Profumo, F.; Zheng Zhang; Tenconi, A, Axial flux machines drives: a new viable solution for electric cars, IEEE Transactions on Industrial Electronics 44 (1997) 39 - 45.

[10] Uler, G.F.; Mohammed, O.A.; Chang-Seop Koh, Design optimization of electrical machines using genetic algorithms", IEEE Trans. Magn. 31 (1994) 2008 -2011.

[11] F. Caricchi, F. Crescimbini, A. Di Napoli, O. Honorati, E. Santini, Compact Wheel Direct Drive for EV's, IEEE Industry Applications Magazine 2 (1996) 25-32.

[12] F. Caricchi, F. Crescimbini, F. Mezzetti, E. Santini, Multi-Stage Axial-Flux PM Machine for Wheel Direct Drive, IEEE Trans. on Industry Application 32 (2000) 882-888.

Sayyed Asghar Gholamian was born in Babolsar, Iran, in 1976. He received a B.Sc. degree in electrical engineering from K.N.Toosi University of Technology, Tehran, Iran in 1999 and a M.Sc. degree in electric power engineering (electrical machines) from university of Mazandaran, Babol, Iran in 2001. He also received the $\mathrm{Ph} . \mathrm{D}$ degree in electrical engineering from K.N.Toosi University of Technology, Tehran, Iran in 2008. He is currently an assistant professor in the department of Electrical Engineering at the Babol University of Technology, Iran. His research interests include power electronic and design, simulation, modeling and control of electrical machines (motor, generator and transformer).

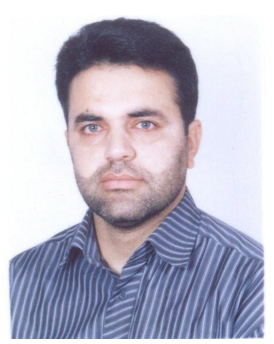

